\title{
Controlled Release Behavior of Temperature Responsive Composite Hydrogel Containing Activated Carbon
}

\author{
Jumi Yun, Ji Sun Im, Donghwee Jin, Young-Seak Lee and Hyung-Il Kim^ \\ Department of Fine Chemical Engineering and Applied Chemistry, BK21- $\mathrm{E}^{2} \mathrm{M}$, \\ Chungnam National University, Daejeon 305-764, Korea \\ ^e-mail:hikim@cnu.ac.kr \\ (Received November 3, 2008; Accepted December 9, 2008)
}

\begin{abstract}
The composites of temperature-sensitive hydrogel and activated carbons were prepared in order to improve both the mechanical strength of hydrogel matrix and the loading capacity of drug in a hydrogel drug delivery system. The swelling of composite hydrogel was varied depending on the temperature. Both the swelling and the release behavior of the composite hydrogel were varied depending on the kind of activated carbon. The release behavior showed the high efficiency which is important for practical applications.
\end{abstract}

Keywords : Drug delivery system, Controlled release, Temperature-sensitive hydrogel, Activated carbon, Mechanical property

\section{Introduction}

Recently, attention has been focused on thermo-sensitive hydrogels and their properties and several review papers have been published[1-5]. Most of the work on thermosensitive hydrogels involves hydrogels based on $\operatorname{poly}(N$ isopropylacrylamide) (PNIPAAm). PNIPAAm hydrogels are well known for their discontinuous phase separation near their phase transition temperature or lower critical solution temperature (LCST) and exhibit a sudden shrinking in volume at a temperature right above LCST at about $32^{\circ} \mathrm{C}[6-10]$. This transition is mainly controlled by the rapid alteration in hydrophilicity and hydrophobicity among the hydrogel subgroups, and thus structural collapse takes place upon heating. However, an obvious limitation of the PNIPAAm hydrogel is its poor mechanical property especially in a highly swollen state when used as a drug delivery device[11-13].

Activated carbon (AC) is one of the most effective adsorbents for organic compounds because of their extended surface area, high adsorption capacity, microporous structure and special surface reactivity[14,15]. Coconut shell carbon has mainly micro-pores to meso-pores whereas coal based carbon has mainly meso-pores and macro-pores.

In this paper, we report our study of PVA/PNIPAAm hydrogels containing activated carbon in order to overcome the shortcomings of PNIPAAm hydrogel. The temperature dependences of the swelling degree and the swelling kinetics were also characterized to determine their thermo-response capability. The application of composite hydrogel to the controlled release of a model drug was also investigated.

\section{Experimental}

\subsection{Materials}

Coal-based activated carbon and coconut-based activated carbon were purchased from Dong Yang Tanso Co. (Korea). Before using them, washing process was carried out at $100^{\circ} \mathrm{C}$ for $2 \mathrm{~h}$ using mixed acids of sulfuric (35 wt\%) and nitric $(20 \mathrm{wt} \%)$ acids with weight ratio of $1: 1$. Poly(vinyl alcohol) (PVA), glutaraldehyde (GA) and potassium persulfate (KPS) used in this study were obtained from Sigma Chemical Company. $N$-Isopropylacrylamide (NIPAAm) was purchased from TCI Co. N,N'-Methylenebisacrylamide (MBAAm) was purchased from Fluka Co. Coomassie brilliant blue R-250, the model drug, was obtained from Biorad.

\subsection{Synthesis of temperature-sensitive hydrogel containing $A C$}

The PVA/PNIPAAm interpenetrating polymer network (IPN) hydrogels were synthesized by the free radical polymerization. The polymerization was carried out in de-ionized water using GA and MBAAm as the crosslinker of PVA and PNIPAAm, respectively. KPS was used as an initiator. They were dissolved to form the aqueous solution with dispersed AC. The reaction mixture was stirred for $30 \mathrm{~min}$ at room temperature. Subsequently, nitrogen was bubbled through the mixture for $20 \mathrm{~min}$ to remove the oxygen dissolved in the reaction mixture. And then, the mixture was reacted by stirring for $2 \mathrm{~h}$ at $70^{\circ} \mathrm{C}$ to produce $\mathrm{AC}$-containing PVA/ 
Table 1. Feed Compositions and Preparation Conditions of ACcontaining PVA/PNIPAAm Composite Hydrogel

\begin{tabular}{lcc}
\hline & $\begin{array}{c}\text { coal-based } \\
\text { AC-containing } \\
\text { hydrogel }\end{array}$ & $\begin{array}{c}\text { coconut-based } \\
\text { AC-containing } \\
\text { hydrogel }\end{array}$ \\
\hline PVA (mol) & 1.84 & 1.84 \\
NIPAAm (mol) & 0.1416 & 0.1416 \\
GA (mol) & 0.16 & 0.16 \\
MBAAm (mol) & 0.00064 & 0.00064 \\
KPS (mol) & 0.05 & 0.05 \\
coal-based AC $(\mathrm{g})$ & 5.0 & - \\
coconut-based AC $(\mathrm{g})$ & - & 5.0 \\
\hline
\end{tabular}

PNIPAAm composite hydrogel. These samples were washed with distilled water at room temperature by replacing with fresh distilled water every few hours. AC-containing PVA/ PNIPAAm composite hydrogel was cut into disc-like pieces having approximately $10 \mathrm{~mm}$ in diameter and $5 \mathrm{~mm}$ in thickness for the following studies. Swollen hydrogel dises were dried in vacuum oven. The feed composition and preparation conditions of AC-containing PVA/PNIPAAm composite hydrogels are summarized in Table 1.

\subsection{Characterization of AC-containing PVA/PNIPAAm composite hydrogels}

\subsubsection{Mechanical property}

The mechanical properties of AC-containing PVA/ PNIPAAm composite hydrogels were measured by an Instron tester model 1122 (Instron Corporation) at $25^{\circ} \mathrm{C}$ (50\% humidity) with a compression load cell, having a fullscale range of $2.0 \mathrm{kN}$. The hydrogel was placed on the top plate of a compression load cell and was compressed between this plate and a cylindrical-shaped metal rod probe (diameter $6.35 \mathrm{~mm}$ ) at a constant cross-head speed of 2.0 $\mathrm{mm} / \mathrm{min}$ until fragmentation of the hydrogel was occurred.

\subsubsection{Swelling behavior of PVA/PNIPAAm hydrogels}

For the equilibrium swelling study, PNIPAAm hydrogels were swollen in distilled water over a temperature range from $4^{\circ} \mathrm{C}$ to $45^{\circ} \mathrm{C}$, which covers the expected range of LCST of the PVA/PNIPAAm hydrogels. The gravimetric method was employed to study the swelling behavior of the hydrogel. The dried hydrogels were immersed into the water of different temperature for a certain period of time until the swelling equilibrium was reached and then these hydrogels were taken out, wiped with tissue paper to remove excess of water on the surface, and weighed immediately. The average values among three measurements were taken for each sample and the equilibrium swelling was calculated as follows:

$$
\text { Swelling }(\%)=(\mathrm{Ws}-\mathrm{Wd}) / \mathrm{Wd} \times 100
$$

where Ws is the weight of a swollen hydrogel at each temperature and Wd is the dry weight of hydrogel.

\subsubsection{Surface morphological analysis}

The surface morphologies of samples were investigated using UHR FE-SEM (ultra-high resolution field emission scanning electron microscope, Hitachi, S-5500) apparatus. These images were obtained after drying in oven at $50^{\circ} \mathrm{C}$ for $24 \mathrm{~h}$. As a pretreatment, samples were vacuumed up to $10^{-3}$ $\mathrm{Pa}$ and sputtered using Pt. SEM images were obtained at 500 resolution.

The interior morphologies of hydrogels were taken by first leaving the hydrogel in distilled water at room temperature to reach an equilibrium state and then freezing it quickly in liquid nitrogen and freeze-drying under vacuum at $-42^{\circ} \mathrm{C}$ for $24 \mathrm{~h}$ until the water was sublimed. The freeze-dried hydrogels were then fractured carefully and the interior morphology of the hydrogels was studied by using a scanning electron microscope.

\subsubsection{BET analysis}

In order to investigate the pore structure such as specific surface area, pore volume, and micropore fraction, BET apparatus (ASAP 2020) was used. Every sample was degassed up to $10^{-3} \mathrm{~Pa}$ and then, nitrogen gas (99.9999\%) adsorption was carried out at $77 \mathrm{~K}$. Specific surface area (S.S.A.) was calculated by using BET equation and the fraction of micropore surface area was measured by $\mathrm{HK}$ (Horvath-Kawazoe) method.

\subsubsection{Release behavior}

Drug release was conducted in the water of 4, 25, 32 and $45^{\circ} \mathrm{C}$. The cumulative amount of released drug was measured by using a UV spectrometer [Optizen 2120 UV, Mecasys, Korea], and a peak search was carried out in order to choose the wavelength range. At each point, the water was removed and replaced with fresh one to reduce the experimental error. As a reference, the drug release experiment using only AC was carried out. All release studies were carried out in triplicate. The results were presented in terms of cumulative release as a function of time.

$$
\text { Cumulative amount released }(\%)=(\mathrm{Mt} / \mathrm{M}) \times 100 \text {, }
$$

where $\mathrm{Mt}$ is the amount of drug released from the composite hydrogel containing $\mathrm{AC}$ at time $\mathrm{t}$ and $\mathrm{M}$ is the amount of coomassie brilliant blue pre-loaded in $\mathrm{AC}$.

\section{Results and Discussion}

\subsection{Pore structure analysis}

The textural properties of two different kinds of activated carbon are presented in Table 2. The BET S.S.A. of coalbased and coconut-based ACs was 890 and $1230 \mathrm{~m}^{2} / \mathrm{g}$, 
Table 2. Textural Properties of the Activated Carbons

\begin{tabular}{cccc}
\hline & BET S.S.A. & $\begin{array}{c}\text { Fraction of } \\
\text { micro S.S.A. }\end{array}$ & Pore volume \\
\hline Coal-based AC & $890 \mathrm{~m}^{2} / \mathrm{g}$ & $43 \%$ & $1.3 \mathrm{cc} / \mathrm{g}$ \\
Coconut-based AC & $1230 \mathrm{~m}^{2} / \mathrm{g}$ & $67 \%$ & $1.5 \mathrm{cc} / \mathrm{g}$ \\
\hline
\end{tabular}

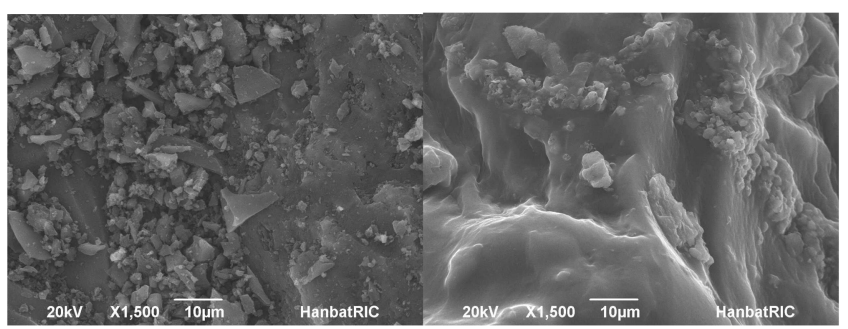

(a)

(b)

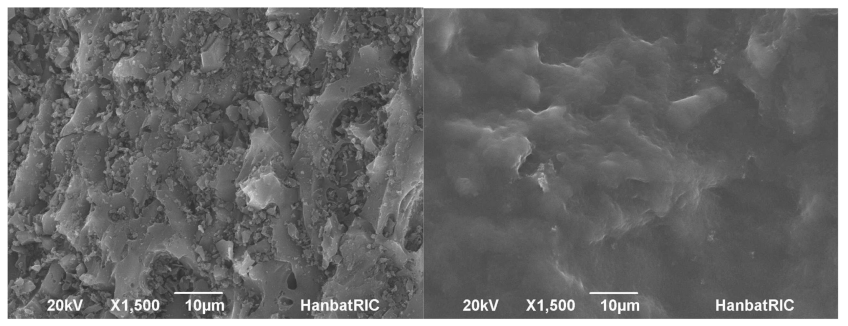

(c)

(d)

Fig. 1. SEM microphotographs of (a) coconut-based AC, (b) PVA/PNIPAAm composite hydrogels containing coconut-based AC (c) coal-based AC and (d) PVA/PNIPAAm composite hydrogels containing coal-based $\mathrm{AC}$, respectively.

respectively. The fraction of micropore structure was 43 and $67 \%$ and the total pore volume was 1.3 and $1.5 \mathrm{cc} / \mathrm{g}$, respectively. The highly developed pore structure contributed to the efficient loading and releasing of the drug due to the excellent adsorbing properties.

\subsection{SEM images of PVA/PNIPAAm hydrogel containing $A C$}

The SEM images of the resulting AC-containing PVA/ PNIPAAm composite hydrogels are presented in Fig. 1. It was clear that AC did exist in the PVA/PNIPAAm hydrogel network to form a new composite system: activated carbon in hydrogel, although some AC was aggregated. As can be seen from Fig. 1, AC was uniformly distributed in the hydrogel matrix and retained the similar surface structure as AC itself.

\subsection{Mechanical property}

The initial compression moduli of the PVA/PNIPAAm hydrogel, coconut-based AC-containing PVA/PNIPAAm composite hydrogel and coal-based AC-containing PVA/ PNIPAAm composite hydrogel were shown in Fig. 2. The

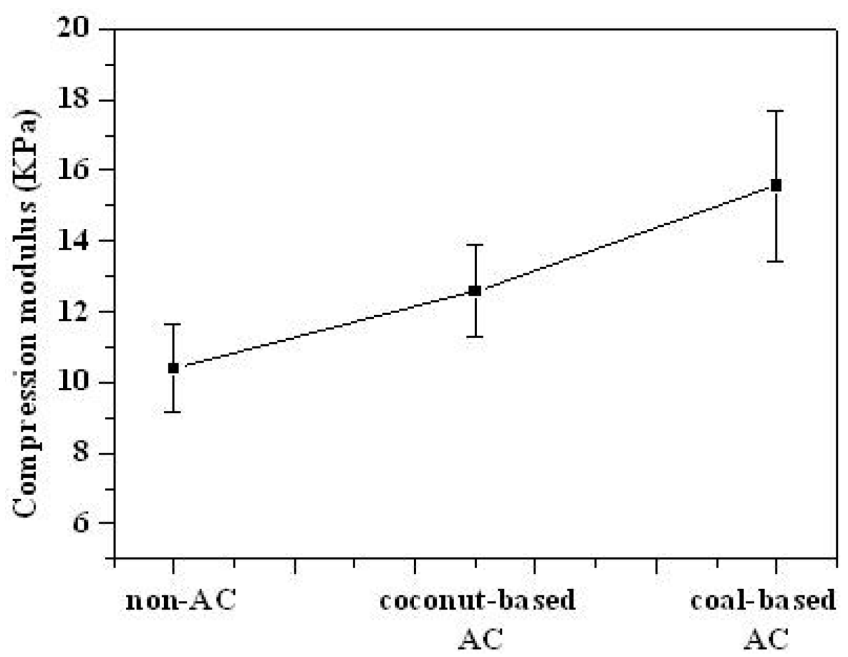

Fig. 2. Compression modulus of AC-containing PVA/PNIPAAm composite hydrogels.

data confirm our original belief that AC-containing PVA/ PNIPAAm composite hydrogel would have better mechanical property than the hydrogel without using AC. It is suggested that the interface between hydrogel and AC leads the positive effect for reducing the impact from outside.

\subsection{Swelling behavior}

Swelling kinetics and temperature-dependent swelling behaviors of PVA/PNIPAAm hydrogels are plotted in Fig. 3. Even though they swelled in all cases, the swelling behavior showed the quite different results. All hydrogels swelled rapidly and reached equilibrium within $48 \mathrm{~h}$. The coconut based AC-containing PVA/PNIPAAm composite hydrogel showed the highest swelling ratio at $4^{\circ} \mathrm{C}$, while the swelling of coal based AC-containing PVA/PNIPAAm composite hydrogel had the lowest swelling degree as seen in Fig. 3. The reason of this temperature-sensitive behavior is that the hydrophilicity of PNIPAAm varies depending on the temperature. The PNIPAAm molecule contains hydrophilic group (amino-, -COHN-) and hydrophobic group (isopropyl-). Extensive hydrogen bonding between hydrophilic groups of the crosslinked PNIPAAm polymer chain and surrounding water molecules leads to the enhanced swelling in water at lower temperatures. The water molecules in the IPN hydrogels are in a bound state at low temperature to induce the swelling.

In order to investigate the reasons of the difference in the swelling ratio in both cases of using coconut based $\mathrm{AC}$ and coal based AC, the chemical structure of surface was studied by using XPS as seen in Fig. 4 and Tables 3 and 4. From the deconvolution of $\mathrm{C} 1 \mathrm{~s}$ peak of two samples, it is sure that the surface of coconut based AC becomes more hydrophilic by acid treatment, because it has more oxygenated $\mathrm{SP}^{3}$ representing hydrophilic functional groups such as $\mathrm{CHx}-\mathrm{OH}$ or $\mathrm{C}$ - 


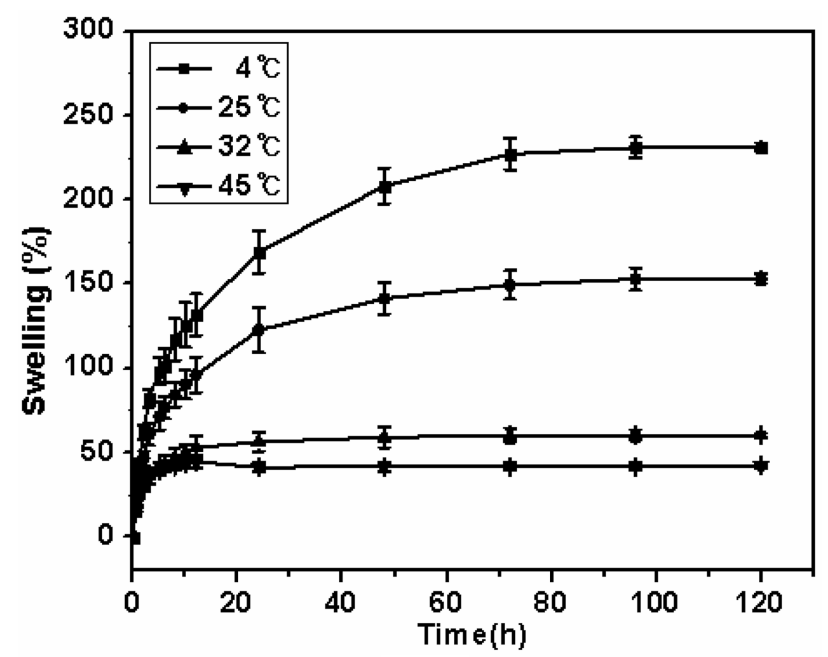

(a)

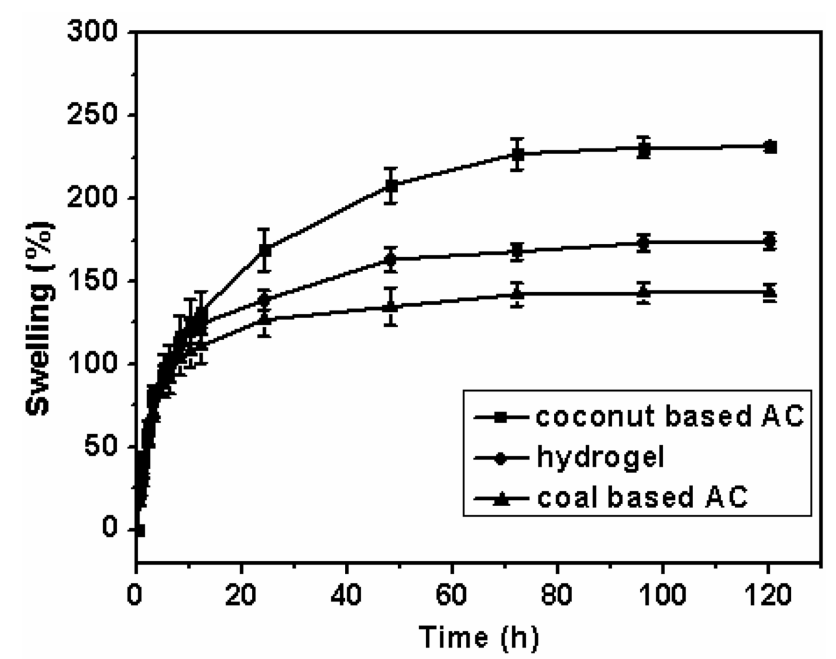

(b)

Fig. 3. Swelling behavior of (a) coconut-based AC-containing PVA/PNIPAAm composite hydrogel at several different temperatures and (b) AC-containing PVA/PNIPAAm composite hydrogel at $4^{\circ} \mathrm{C}$.

O-C. The increased hydrophilicity of AC is believed to play an important role in the higher swelling of the acid treated coconut based AC-containing PVA/PNIPAAm composite hydrogel.

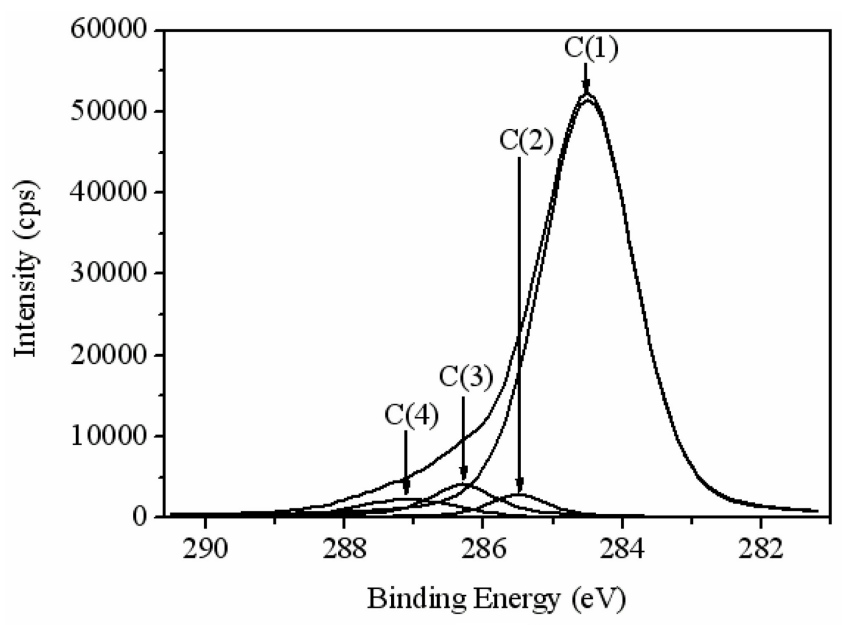

(a)

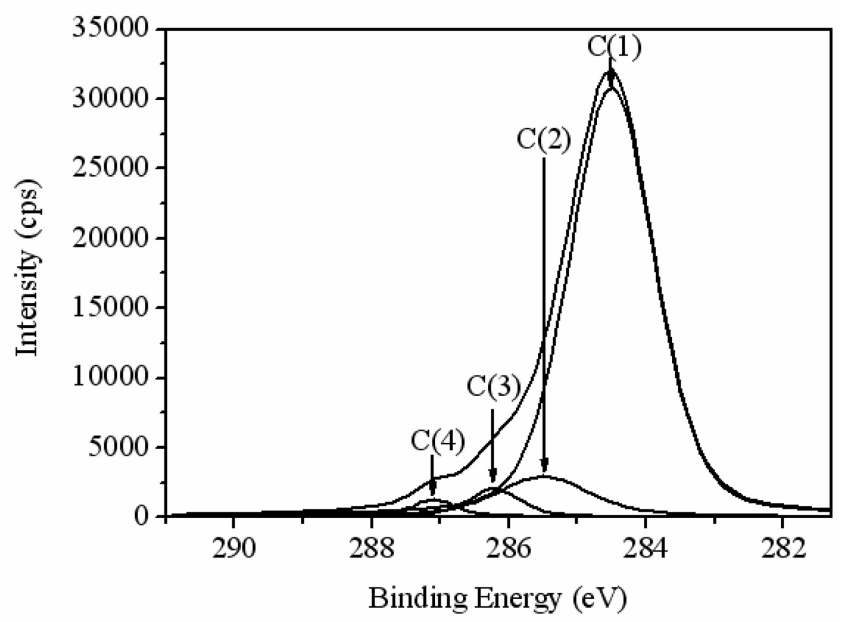

(b)

Fig. 4. Deconvolution of the core level C1s spectra (a) coconut based AC and (b) coal based AC.

\subsection{Drug release behavior}

Coomassie brilliant blue was used as a model drug. The drug release profile from AC-containing PVA/PNIPAAm composite hydrogels is shown in Fig. 4. The released amount of drug from the AC-containing PVA/PNIPAAm

Table 3. Energy Shifts and Assignments of the Different Component of C1s Spectra

\begin{tabular}{|c|c|c|}
\hline Component & $\mathrm{C}(\mathrm{i})-\mathrm{C}(1)(\mathrm{eV})$ & Assignment \\
\hline $\mathrm{C}(1)$ & - & Non-functionalized $\mathrm{sp}^{2}$ and $\mathrm{sp}^{3} \mathrm{C}$ atoms \\
\hline$C(2)$ & 1.0 & Aliphatic non-functionalized $\mathrm{sp}^{3} \mathrm{C}$ \\
\hline $\mathrm{C}(3)$ & 1.8 & $\begin{array}{l}\text { Non-functionalized } \mathrm{sp}^{2} \mathrm{C} \\
\text { Non-functionalized } \mathrm{sp}^{2} \mathrm{C} \text { or } \mathrm{sp}^{3} \mathrm{C} \\
\mathrm{sp}^{2} \mathrm{C} \text { bound to an oxygen atom ( } \mathrm{phenol} \text {, phenyl ether) }\end{array}$ \\
\hline $\mathrm{C}(4)$ & 2.6 & $\begin{array}{l}\text { Non-functionalized } \mathrm{sp}^{2} \mathrm{C} \text { or } \mathrm{sp}^{3} \mathrm{C} \\
\text { Oxygenated } \mathrm{sp}^{3} \mathrm{C} \text { in a non-functionalized environment }\left(\mathrm{CH}_{X}-\mathrm{OH} \text {, or } \mathrm{C}-\mathrm{O}-\mathrm{C}\right)\end{array}$ \\
\hline
\end{tabular}


Table 4. C1s Peak Parameters of ACs

\begin{tabular}{|c|c|c|c|c|c|c|}
\hline \multirow[t]{2}{*}{ Component } & \multicolumn{3}{|c|}{ Coal-based activated carbon } & \multicolumn{3}{|c|}{ Coconut-based activated carbon } \\
\hline & Peak Position (eV) & FWHM (eV) & Concentration $(\%)$ & Peak Position (eV) & FWHM (eV) & Concentration (\%) \\
\hline $\mathrm{C}(1)$ & 284.5 & 1.46 & 84.0 & 284.5 & 1.56 & 85.9 \\
\hline$C(2)$ & 285.5 & 1.62 & 9.9 & 285.5 & 1.14 & 6.2 \\
\hline $\mathrm{C}(3)$ & 286.3 & 0.91 & 3.8 & 286.3 & 0.99 & 4.2 \\
\hline$C(4)$ & 287.1 & 0.74 & 2.3 & 287.1 & 1.78 & 3.7 \\
\hline
\end{tabular}

composite hydrogel was increased rapidly at $4^{\circ} \mathrm{C}$ due to a larger swelling of matrix. The temperature-responsive hydrogel matrix could control the release of drug depending on the degree of swelling.

The characteristic morphology, which was changed by

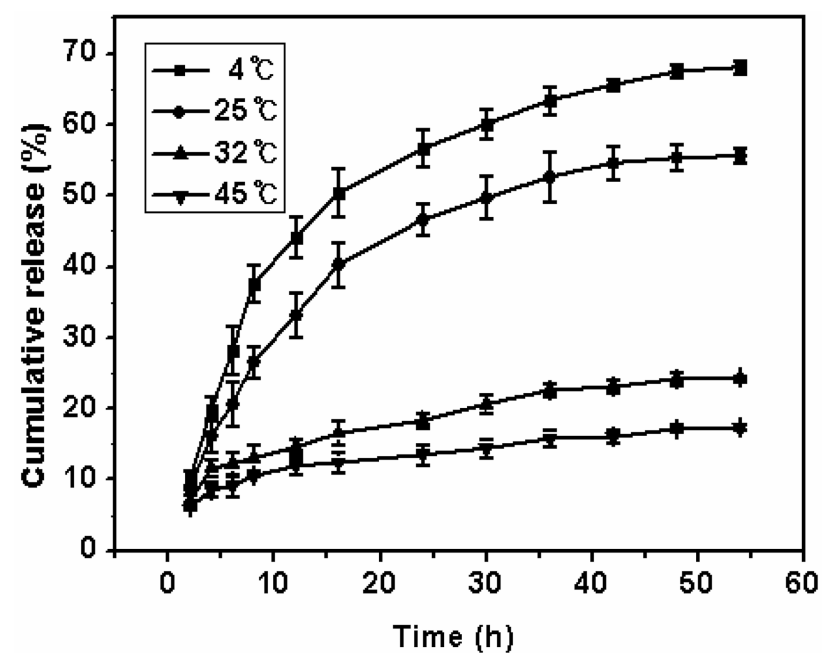

(a)

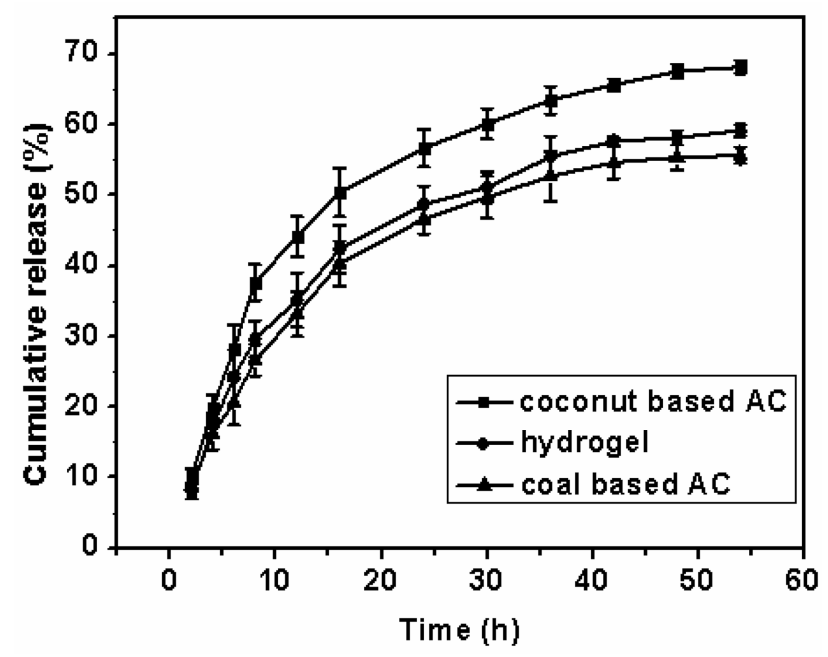

(b)

Fig. 5. Drug release behavior of (a) coconut-based AC-containing PVA/PNIPAAm composite hydrogel at several different temperatures and (b) AC-containing PVA/PNIPAAm composite hydrogel at $4^{\circ} \mathrm{C}$. temperature, of the freeze-dried samples of the swollen hydrogel was studied by SEM as shown in Fig. 5. The void size in surface is greatly temperature-dependent because of the temperature-sensitive swelling of hydrogel matrixs. This structural change must result from the interactions among the hydrogel networks absorbing water molecules. This controllable void size is applied beneficially to the current drug delivery systems.

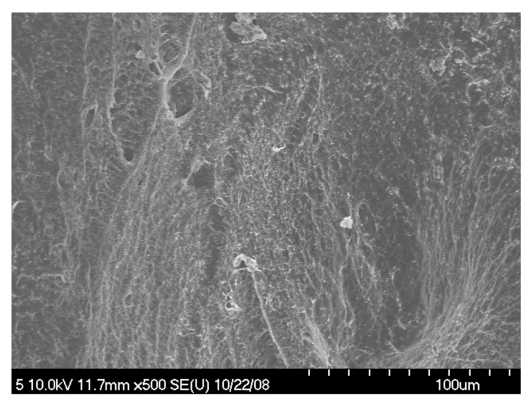

(a)

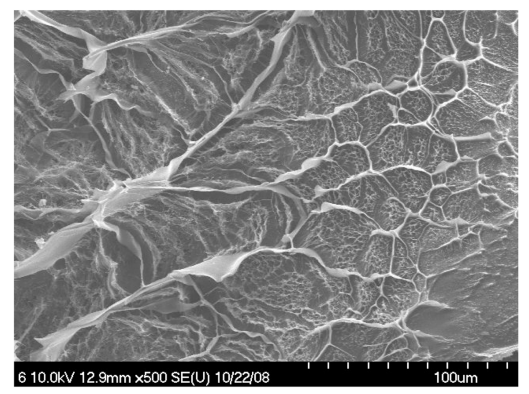

(b)

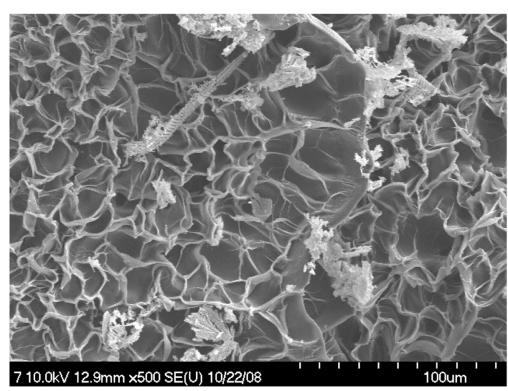

(c)

Fig. 6. SEM microphotographs of the freeze-dried coconutbased AC-containing PVA/PNIPAAm composite hydrogel swollen at (a) $4{ }^{\circ} \mathrm{C}$, (b) $25^{\circ} \mathrm{C}$, and (c) $45^{\circ} \mathrm{C}$, respectively. 


\section{Conclusions}

The composites of temperature-sensitive PVA/PNIAAm hydrogel with two different kinds of activated carbons were prepared. In the case of swelling, the coconut-based ACcontaining PVA/PNIAAm composite hydrogel showed the highest swelling ratio at $4^{\circ} \mathrm{C}$, while the coal-based $\mathrm{AC}$ containing PVA/PNIPAAm composite hydrogel had the lowest swelling. The released amount of drug from the coconut-based AC-containing PVA/PNIPAAm composite hydrogel was increased rapidly at $4^{\circ} \mathrm{C}$ due to the extensively developed pore structure of hydrogel and the hydrophilic surface nature of AC. The coconut-based AC was suggested as an effective adsorbent of drug in the drug delivery system using a temperature-sensitive hydrogel.

\section{Acknowledgement}

This study was finalcially supported by Korea Industrial Technology Foundation (KOTEF).

\section{References}

[1] Zhang, X. Z.; Zhuo, R. X.; Cui, J. Z.; Zhang, J. T. Inter. J. Pharm. 2002, 235, 43.
[2] Bae, Y. H.; Okano, T.; Kim, S. W. J. Polym. Sci., Part B, Polym. Phys. 1990, 28, 923.

[3] Zhang, X. Z.; Wang, F. J.; Chu, C. C. J. Mater. Sci. Mater. Med. 2003, 14, 451.

[4] Zhang, X.; Wu, D.; Chu, C.C. Biomaterials 2004, 25, 4719.

[5] Verestiuc, L.; Ivanov, C.; Barbu, E.; Tsibouklis, J. Int. J. Pharm. 2004, 269, 185.

[6] Hirokawa, Y.; Tanaka, T. J. Chem. Phys. 1984, 81, 6379.

[7] Inomata, H.; Wada, N.; Yagi, Y.; Goto, S.; Saito, S. Polymer 1995, 36, 875.

[8] Jeong, B.; Bae, Y. H.; Lee, D. S.; Kim, S. W. Nature 1997, $388,860$.

[9] Jeong, B. Kim, S. W.; Bae, Y. H. Adv. Drug. Deliv. Rev. 2002, 54, 37.

[10] Vernon, B.; Kim, S. W.; Bae. Y. H. J. Biomed. Mater. Res. 2000, 51, 69 .

[11] Gutowska, A.; Bark, J. S.; Kwon, I. C.; Bae, Y. H.; Cha, Y.; Kim, S. W. J. Control. Rel. 1997, 48, 141.

[12] Alvarez-Lorenzo, C.; Concheiro, A. J. Control. Rel. 2002, 80, 247.

[13] Zhang, X. Z.; Zhuo, R. X.; Cui, J. Z.; Zhang, J. T. Inter. J. Pharm. 2002, 235, 43.

[14] Anson, M.; Marchese, J.; Garis, E.; Ochoa, N.; Pagliero, C. J. Memb. Sci. 2004, 243, 19.

[15] Ballinas, L.; Torras, C.; Fierro, V.; Garcia-Valls, R. J. Phys. Chem. Solids 2004, 65, 633. 